\title{
Aplicação do programa $5 S$ no supermercado Beira Lago, em entre Rios do Oeste
}

O presente artigo foi desenvolvido com o objetivo de analisar os resultados obtidos na aplicação da ferramenta administrativa $5 \mathrm{~S}$ e seus reflexos na sustentabilidade empresarial. Para esse fim, apresentou-se os passos que devem ser seguidos para implantar o programa, relacionou-se o antes e o depois da realização do estudo, apresentou-se as vantagens obtidas após a inserção do método e analisou-se as aplicações da pesquisa efetuada. Optou-se por uma abordagem qualitativa do problema; para a coleta de dados foram utilizados os métodos da observação e da pesquisa-ação, visto que, na aplicação do estudo, os pesquisadores foram mais que meros observadores. Dentre os resultados obtidos na pesquisa, destacam-se principalmente as vantagens resultantes, como a eliminação do desperdício, a otimização do espaço, a melhoria nas relações humanas, a prevenção de quebras, a autodisciplina, o incremento da eficiência, o aumento da produtividade, a maior facilidade na tomada de decisões, a melhoria da qualidade, a padronização, o aumento da segurança e a racionalização do tempo. Como limitação, observase que os resultados de aplicação deste estudo não podem ser generalizados para outros supermercados, pois foi aplicado em uma única empresa, sendo necessária a reaplicação do programa para posteriores comparações. Entretanto, está disponível para a utilização em posteriores estudos e para melhorar a qualidade do serviço oferecido pelas empresas.

Palavras-chave: Programa 5S; Ferramentas administrativas; Aumento de produtividade.

\section{Application of the $5 S$ program at Beira Lago supermarket, in Entre Rios do Oeste}

\begin{abstract}
This article was developed with the objective of analyzing the results obtained in the application of the $5 S$ administrative tool and its effects on corporate sustainability. To this end, we presented the steps that should be followed to implement the program, related before and after the study, presented the advantages obtained after the insertion of the method and analyzed the research applications. made. We opted for a qualitative approach to the problem; For data collection, observation and action research methods were used, since, in the application of the study, researchers were more than mere observers. Among the results obtained in the research, we highlight the resulting advantages, such as the elimination of waste, the optimization of space, the improvement of human relations, the prevention of breakage, self-discipline, increased efficiency, increased productivity, easier decision-making, quality improvement, standardization, increased safety and rationalization of time. As a limitation, it is observed that the results of the application of this study cannot be generalized to other supermarkets, as it was applied in a single company, requiring the application of the program for further comparisons. However, it is available for use in further studies and to improve the quality of service offered by companies.
\end{abstract}

Keywords: 5S Program; Administrative tools; Productivity increase.

Topic: Teoria Geral da Administração

Reviewed anonymously in the process of blind peer.
Received: $15 / 10 / 2019$

Approved: 21/12/2019
Taís Regina Schlindwein Heidrich

Universidade Estadual do Oeste do Paraná, Brasil tais199910@hotmail.com

\section{José Angelo Nicácio}

Universidade Estadual do Oeste do Paraná, Brasil http://lattes.cnpq.br/5136632173025604

janicacio@hotmail.com

\section{Silvana Anita Walter (iD}

Universidade Estadual do Oeste do Paraná, Brasil

http://lattes.cnpq.br/6055446867536139

http://orcid.org/0000-0003-1684-5465

silvanaanita.walter@gmail.com d

DOI: 10.6008/CBPC2179-684X.2019.004.0001
Referencing this:

HEIDRICH, T. R. S.; NICÁCIO, J. A.; WALTER, S. A.. Aplicação do programa $5 S$ no supermercado Beira Lago, em entre Rios do Oeste. Revista Brasileira de Administração Científica, v.10, n.4, p.1-15, 2019. DOI: http://doi.org/10.6008/CBPC2179-684X.2019.004.0001 


\section{INTRODUÇÃO}

A preocupação com a gestão da qualidade surgiu no início do século XX, quando os Estados Unidos se tornou uma nação industrialmente desenvolvida (JURAN et al., 1991). O programa $5 S$ foi criado na década de 1950, por Kaoru Ishikawa, para agregar qualidade e produtividade nas empresas japonesas no período pós-2a Guerra Mundial (FREITAS et al., 2015). No Brasil, o 5S foi disseminado em várias empresas como uma ferramenta administrativa, tentando educar os gestores e os colaboradores com a prática de alguns hábitos, em que os resultados aferem os benefícios da aplicação do mesmo (SILVA, 2001). As três últimas décadas foram representadas por várias novidades em relação ao conteúdo de auxílio na gestão para dar suporte às organizações, fazendo com que as mesmas se mantenham atuantes, qualificadas, competitivas e capacitadas para o mercado (MODELL, 2009; LIVRAMENTO et al., 2015).

Diante de um ponto de incerteza, a sociedade muda com intensidade e rapidez, gerando resultados extraordinários e ocasionando insegurança e imprevisibilidade para as organizações. A adoção de ferramentas administrativas é de fundamental importância para contribuir com a gestão organizacional, pois ajudam na interpretação e na solução dos problemas por meio da observação e da descrição detalhada do levantamento de fatores ou causas correlatas (ROSSATO et al., 2016).

Essas ferramentas corroboram para a organização, principalmente no aspecto da qualidade, estabelecendo prioridades, aumentando a produtividade e facilitando na tomada de decisões (MILLER, 1996). Dentre várias técnicas administrativas, encontram-se: Ciclo PDCA, Seis Sigmas, Benchmarking, Diagrama de Causa e Efeito, Kanban, 5W2H, Programa 5S, entre outros.

A aplicação do programa 5S, objetivo de análise deste estudo, proporciona inúmeros resultados positivos, tanto para a organização da empresa, quanto para os seus trabalhadores. Entre os benefícios obtidos, pode-se citar: eliminação do desperdício, otimização do espaço, melhoria nas relações humanas, prevenção de quebras, autodisciplina, incremento da eficiência, aumento da produtividade, maior facilidade na tomada de decisões, melhoria da qualidade, padronização, aumento da segurança, racionalização do tempo (MARSHALL, 2012; DUARTE et al., 2013).

Um dos principais pontos que liga o programa à atualidade é sua questão ambiental. Isso significa que, além de limpar e eliminar itens, é preciso identificar a fonte de sujeira, suas respectivas causas, evitando que isto ocorra novamente. Desta forma, elimina-se todo e qualquer tipo de poluição, seja esta sonora, visual ou ambiental, dando a destinação correta aos itens para descarte (SANTOS et al., 2006; ROSSATO et al., 2016).

Independente do porte da empresa (micro, pequena, média ou grande), a maioria delas enfrentam os mesmos problemas gerais sem a aplicação e a prática do programa $5 \mathrm{~S}$, tais como, falta de organização nas tarefas diárias e má distribuição das mesmas, acúmulo de documentos e itens desnecessários, ambiente de trabalho sujo, não padronização ao realizar o trabalho, entre outros. Estes problemas, normalmente, geram um resultado negativo na organização e impactam as expectativas do cliente. Para isto, as empresas utilizam do programa, com o intuito de diminuir ou anular estes erros (COSTA et al., 2017). 
Partindo dos fatores que envolvem a busca pela qualidade e para facilitar as técnicas de gestão, temse como questão norteadora deste artigo: quais os principais resultados obtidos por meio da aplicação do programa $5 \mathrm{~S}$ no Supermercado Beira Lago, localizado na cidade de Entre Rios do Oeste - Paraná?. Dessa forma, este estudo tem por objetivo analisar os resultados obtidos na aplicação da ferramenta administrativa 5S e seus reflexos na sustentabilidade empresarial. Para esse fim, decorreu-se algumas etapas: a) apresentar os passos que devem ser seguidos para implantar o programa; b) relacionar o antes e o depois da realização do estudo; c) apresentar as vantagens obtidas após a inserção do método e d) analisar as aplicações da pesquisa efetuada.

A pesquisa é constituída, além desta introdução, em mais quatro etapas: na segunda, desenvolve-se a fundamentação teórica, na qual encontram-se os principais conceitos, as características relacionadas a aplicação do programa, além de abranger a explicação de outras ferramentas ligadas à área administrativa; na terceira, relata-se os procedimentos metodológicos empregados para o desenvolvimento da pesquisa; na quarta, exibe-se a análise dos resultados identificados por meio da aplicação e, na quinta, apresentam-se as conclusões e as considerações finais do estudo realizado.

\section{REVISÃO TEÓRICA}

Nesta sessão são abordados os seguintes temas: gestão da qualidade total e gestão de processos, que consiste na definição e na relação do mesmo com o programa; ferramentas de qualidade, apresentando outras abordagens relacionadas que apoiam a qualidade e a gestão; o programa $5 S$, que consiste na explicação do mesmo de maneira mais aprofundada e a triple bottom line, que consiste na relação da sustentabilidade empresarial com o programa $5 \mathrm{~S}$.

\section{Gestão da Qualidade Total}

Resumidamente, a qualidade pode ser conceituada como a busca pela perfeição, com a finalidade de satisfazer os clientes que estão cada vez mais informados a respeito das facilidades de consumo e da ampla variedade de organizações do mercado que Ihes oferece produtos e serviços. Além disso, a qualidade é a eliminação do retrabalho (refazer o que estava pronto por existir algum erro ou falha) e isto não pode se afastar das organizações que desejem permanência e lucro.

A gestão da qualidade, por sua vez, é um processo ininterrupto, que recebe resultados mais concretos a longo prazo. É um conjunto de planos e de estratégias que buscam o desenvolvimento e o acompanhamento da empresa, sendo assim , torna-se abrangente e evolutiva (NETO, 2008). Já, a qualidade total é a capacidade que um produto ou serviço tem de satisfazer as necessidades, as exigências e as expectativas do cliente, sejam eles internos ou externos à organização. O principal foco é a maximização da qualidade em todos os aspectos e fases das atividades de uma empresa, envolvendo todos os colaboradores, visando erradicar os defeitos e as perdas das operações, buscando alcançar a efetiva e a completa satisfação dos clientes (PANCHAL, 2012).

A Gestão da Qualidade Total (em inglês, Total Quality Management, doravante TQM), é 
principalmente, o progresso contínuo da qualidade dos bens e dos serviços oferecidos, dentro da participação de todos os indivíduos, independente de níveis ou funções, englobando desde os altos cargos até o chão de fábrica da organização (SIDDIQUI et al., 2009).

A adoção de um sistema como o TQM, requer amplas mudanças em todos os aspectos de uma organização: na sua força de trabalho, na sua gestão, na sua estrutura e na sua cultura. Para o acompanhamento desta qualidade, tem-se a utilização do controle de qualidade. O controle de qualidade é um sistema dinâmico e complexo, que envolve direta ou indiretamente todos os setores da organização, com o intuito de melhorar e assegurar a qualidade do produto final (LEVIS et al., 2008).

\section{Gestão de processos}

Toda organização, seja ela, pública ou privada, deve empregar-se de vários processos interrelacionados com o propósito de conquistar suas metas e seus objetivos. Desta forma, os processos têm uma sequência, respeitando o espaço e o tempo, obtendo um resultado específico e buscando atender todas as necessidades e desejos dos consumidores (DAVENPORT, 1994). Estes processos são realizados de maneira contínua pelos colaboradores. A atenção às pessoas é um dos pontos da gestão de processos mais fundamentais, pois quando os processos são efetivados com êxito pelos funcionários, ocorre-se o alcance das metas da empresa, agregando valor ao cliente (DOMINGUES et al., 2015).

Grande parte da melhoria dos processos são baseadas na utilização de tecnologia, porém o elemento humano é fundamental, pois este realiza todas as atividades, atendendo à variadas demandas que sobrevêm esse fato (FALCÃO JÚNIOR, 2016). Desta forma, são pessoas, motivadas e capacitadas, que realizam e contribuem com os resultados de uma organização.

Ainda que a melhoria de processos traga inúmeros resultados positivos para a organização, alerta-se sobre os obstáculos que podem dificultar ou impedir a realização deste tipo de gestão nas organizações, como: a cultura organizacional, a falta de comprometimento e de capacitação para os funcionários, a infraestrutura precária, a falta de apoio da alta administração, a resistência às mudanças de ambiente interno, a falta da visão por processos, entre outros (CARVALHO, 2015).

\section{Ferramentas administrativas de qualidade}

As ferramentas administrativas são fundamentais para o processo de gestão da qualidade. Estes instrumentos apoiam na descoberta dos fatores que geram o problema e ajudam a empresa no seu processo decisório, auxiliando na tomada de prioridades, facilitando na resolução de alguma dificuldade que a empresa esteja passando e na execução de melhorias internas (KAPUR et al., 2018).

As ferramentas administrativas retratam um conjunto de práticas disponíveis para o uso no sistema de gestão da qualidade total das empresas e são implantados pela empresa, à medida que surgem necessidades específicas (PATEL et al., 2014). Desta forma, destacam-se algumas, tais como: Ciclo PDCA, Seis Sigmas, Benchmarking, Diagrama de Causa e Efeito, Kanban, 5W2H, apontando maior ênfase ao programa $5 \mathrm{~S}$, objeto deste estudo. 
a) Ciclo PDCA: tem origem americana e é utilizado para melhoria e padronização dos processos; auxilia na tomada de decisões, atuando de forma direta no alcance dos mesmos, definindo como as mudanças devem ser feitas na empresa. O Ciclo é composto de quatro estágios: planejamento (plan), execução (do), verificação (check) e ação (ac) (MATSUO et al., 2013);

b) Seis sigmas: abordagem que impulsiona a melhoria do desempenho e a valorização da satisfação dos clientes. Seu princípio fundamental consiste em reduzir continuamente a variação nos processos, eliminando as falhas ou os defeitos nos produtos e nos serviços prestados (LANCASTER, 2011);

c) Benchmarking: compara e busca processos e/ou desempenhos para criar uma forma melhor de fazer a mesma coisa; identifica um ponto de referência, na qual as atividades são medidas e avaliadas dentro de um processo de melhoria contínua (MARSHALL JUNIOR, 2011);

d) Diagrama de causa e efeito: é também conhecido como diagrama de Ishikawa ou diagrama espinha de peixe. Consiste em um sistema de representação gráfica que analisa os possíveis fatores (causa) de um problema que geram um impacto (efeito). As causas podem estar classificadas em seis grupos denominados 6Ms: método, mão de obra, meio ambiente, medição, material e máquina. Proporciona ampliar a visão das possíveis causas de um problema, enriquecendo a sua análise e a identificação de soluções (SHAH et al., 2013);

e) Diagrama de Pareto: trata-se de uma ferramenta de priorização, classificando os problemas que possuem maior frequência ou ocorrência; facilita a atuação da organização, já que terá mais atenção e esforços para os problemas "mais impactantes e frequentes" (RORIZ et al., 2017);

f) Kanban: utilizado para controlar e para programar a produção usada na administração do just in time. É composto por cartões visuais e por quadros que auxiliam no planejamento da produção; controlando o fluxo e a movimentação dos materiais distribuídos ou recebidos de fornecedores e tentando diminuir o estoque o mínimo possível (BALLESTERO-ALVAREZ, 2010);

g) 5W2H: utilizada na padronização e no mapeamento de processos, na elaboração de planos de ação e no estabelecimento de processos relacionados a indicadores. Recebe este nome, pois tem associação à primeira letra das palavras inglesas: why (por que), what (o que), where (onde), when (quando), who (quem), how (como) e how much (quanto custa). Surge então, o 5W3H, acrescentando how many (quantos) (SINGH et al., 2014).

Destaca-se, embora não sendo uma ferramenta de gestão, o Brainstorming, que tem como finalidade novas ideias com um enfoque dentro de um meio sem inibições, ou seja, diversifica opiniões dentro de um processo de criatividade grupal. É desenvolvido em três fases: apresentação do assunto, problema, geração e documentação das ideias e, por fim, análise e seleção (URBAN, 2015).

O mesmo caso acontece com o fluxograma, que permite mapear as etapas do processo em sua sequência de execução. O fluxograma é uma representação gráfica da rotina de um processo, por meio de símbolos padronizados, permitindo assim, o mapeamento individualizado de cada etapa pela sequência lógica das atividades (SORTE, 2014). 


\section{O programa $5 S$}

O Programa 5S (em japonês) ou Housekeeping (em inglês) é uma técnica administrativa de origem japonesa criada por Takashi Osada, no início dos anos 80, com o intuito de aumentar a qualidade e a produtividade. Envolve um conjunto de cinco sensos que tentam melhor organizar um local. Um ambiente bem organizado traz facilidade para que os colaboradores realizem suas funções com maior rapidez e eficiência, otimizando suas atividades e buscando melhores resultados com menor esforço (LAPA et al., 1998)

Neste sentido, a técnica busca mudanças que consistem no conhecimento de informações e no empenho das pessoas em práticas participativas, como um processo educacional, em que há a prática da seleção de itens necessários, limpeza, padronização e disciplina na realização das tarefas diárias, promovendo assim, mudanças comportamentais (SOROOSHIAN et al., 2012). Os cinco sensos do programa $5 S$ tem origem das iniciais dos nomes das cinco atividades em japonês que designam cada fase de implantação e começam com a letra S, são estes:

a) SEIRI (senso de utilização): este é o senso em que cada colaborador deve saber diferenciar o útil do inútil, pois somente o que tem utilidade deve estar no local. Trata-se da classificação dos itens que se encontram dentro do ambiente, separando e definindo o que fica e o que vai embora, utilizando os recursos de acordo com a necessidade e adequação e evitando excessos, desperdícios e má utilização (OLIVEIRA, 2013);

b) SEITON (senso de arrumação): trata-se de definir locais para armazenar as coisas partindo do seu nível de utilização, onde os itens mais utilizados estejam em melhor acesso, identificados e sinalizandos para que sejam fáceis e rápidos de encontrar, ou caso os materiais terminem, para que sejam repostos. É pensar no layout da empresa (BALLESTERO-ALVAREZ, 2010);

c) SEISOU (senso de limpeza): o colaborador deve saber da importância de estar em um ambiente limpo, pois este passa qualidade e segurança para as demais pessoas que estão naquele local. Deve-se limpar a área e descobrir quais as rotinas ou trabalhos que geram sujeira, modificando-as quando necessário. Sujeira é tudo que agride o meio ambiente, não sendo apenas poeira, manchas, barro, etc.. Considera-se, também, iluminação deficiente, mau cheiro, ruídos, pouca ventilação, entre outros. Sendo assim, mais importante que limpar, é não sujar (ROSSATO et al., 2016);

d) SEIKETSU (senso de padronização/asseio): procura padronizar e manter os três primeiros passos diariamente, tornando saudável o ambiente de trabalho para os funcionários e para os clientes. Neste senso, devemos avaliar e administrar os resultados já alcançados e verificar as coisas que ainda podem ser melhoradas. Os autores chamam, também, de senso de asseio, que significa ter comportamento ético, promovendo um ambiente saudável nas relações interpessoais, sejam elas, sociais, familiares ou profissionais, em que se cultiva um clima de respeito mútuo (LAPA et al., 1998);

e) SHITSUKE (senso de autodisciplina): disciplina diz respeito a roteirização da melhoria alcançada, buscando a obediência à rotina e constantes avanços na educação do ser humano. O senso de autodisciplina desenvolve o hábito de observar e seguir regras, procedimentos, normas, sejam estas informais ou escritas, 
respeitando o espaço (LAPA et al., 1998).

Algumas das vantagens oferecidas pelo programa $5 \mathrm{~S}$ são: eliminação de documentos desnecessários, melhoria na comunicação interna, melhoria na acessibilidade de itens, maior aproveitamento dos espaços internos, melhoria do layout, melhoria do aspecto visual das áreas, maior limpeza no ambiente, padronização de tarefas, maior participação dos colaboradores, economia de tempo e de esforço, maior eficiência, maior agilidade, diminuição de custos, entre outros, promovendo, assim, uma melhora geral do ambiente de trabalho (MOHAMMAD, 2017).

\section{Triple botton line}

O tripé da sustentabilidade ficou bastante conhecido pelas empresas e pelos pesquisadores como uma ferramenta conceitual vantajosa, utilizada para interpretação da importância de uma visão sustentável mais ampla. Desta forma, se faz necessário salientar ações dentro dos três princípios básicos da sustentabilidade (triple bottom line) (SENTANIN et al., 2008).

Estes princípios são: aspectos econômicos, sociais e ambientais. Assim, quando uma organização cria uma ação sustentável, ela irá respaldar se a mesma é economicamente viável, atuando de forma socialmente responsável e ambientalmente correta, atendendo todos os interesses, tantos dos que afetam, quanto os que são afetados por suas atividades (CARVALHO et al., 1998).

Pode-se citar alguns dos benefícios encontrados com a utilização do tripé da sustentabilidade, como: vantagem competitiva, produto de qualidade com menor custo, estratégias de negócios, tecnologias limpas, reciclagem, utilização sustentável de recursos naturais, atendimento à legislação, produtos ecologicamente corretos, promoção e participação em projetos de cunho social (CORAL, 2002).

\section{METODOLOGIA}

Para analisar os resultados obtidos por meio da aplicação do programa 5S no Supermercado Beira Lago, localizado na cidade de Entre Rios do Oeste, no Paraná, optou-se por uma abordagem qualitativa do problema, ressaltando que a divulgação das informações desta empresa foi autorizada pelos devidos representantes. Quanto a finalidade, esta pesquisa caracteriza-se como explicativa, pois objetiva identificar os fatores que determinam ou contribuem para a ocorrência dos fenômenos (RAUPP et al., 2009).

Para a coleta de dados foram utilizados os métodos da observação e da pesquisa-ação, visto que, na aplicação do estudo, os pesquisadores foram mais que meros observadores. A pesquisa-ação tem uma interferência direta no problema, buscando encontrar uma solução e, simultaneamente, colaborar com a ciência, incluindo todos os colaboradores e promovendo a interatividade e a cooperação entre os envolvidos (THIOLLENT, 1997). Desta forma, foi possível: visualizar e diagnosticar a necessidade de melhorias nos diversos ambientes, assim como as deficiências na estrutura física e os problemas de ordem comportamental da organização; formular estratégias de ação; desenvolver essas estratégias e avaliar sua eficiência; ampliar a compreensão da nova situação; estabelecer uma metodologia para a implantação do programa que pode ser utilizada por outras organizações. 
Não existe uma descrição única explicando o passo a passo da implementação do programa. Existem apenas orientações básicas de cada um dos sensos (LIMA,1998). Sendo assim, a implementação do programa ocorreu da seguinte forma: conscientizou-se os colaboradores sobre o que é a ferramenta 5S; desenvolveuse o senso de utilização, de arrumação e de limpeza nos ambientes de trabalho; explicou-se aos funcionários sobre a importância da padronização das atividades da empresa e criou-se o hábito do senso da autodisciplina no dia a dia da organização.

Primeiramente, para que houvesse a conscientização sobre o que é a ferramenta 5S, realizou-se uma reunião com o gerente e apresentou-se o assunto a todos os colaboradores, destacando a atual posição do supermercado e a posição que se almejava conquistar. Em seguida, para efetivação do primeiro senso, o senso de utilização, buscou-se a liberação de áreas no local de trabalho, identificando os itens necessários e desnecessários e mantendo apenas o que realmente tinha necessidade. Na figura 1, descreve-se como efetivou-se a separação, a classificação e a armazenagem dos itens.

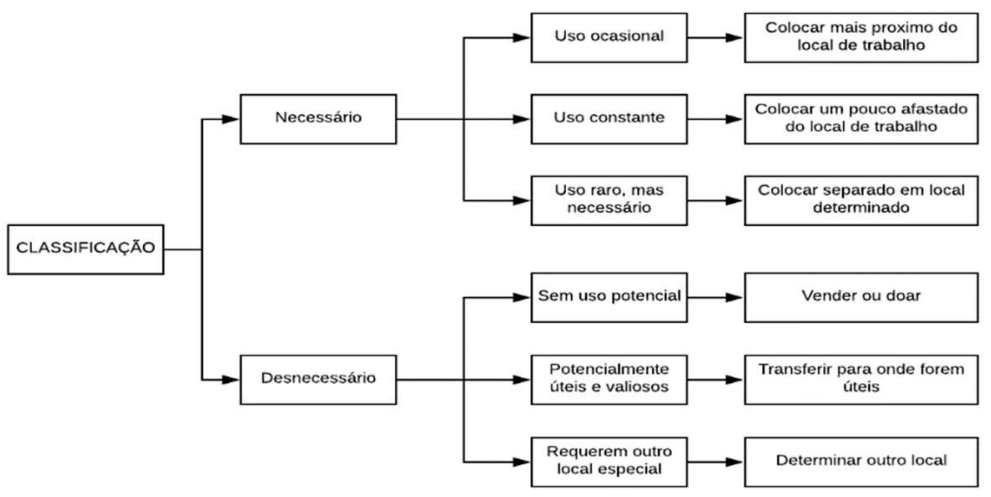

Figura 1: Classificação dos objetos e dados. Fonte: Rossato et al. (2016).

No segundo passo, senso de arrumação, procurou-se organizar os setores e suas dependências, estudando possíveis melhorias no layout (disposição de mesas, armários, materiais etc.) Para aplicar o senso de arrumação nos ambientes de trabalho, determinou-se o local para guardar os documentos, os materiais e os equipamentos necessários; padronizou-se a nomenclatura não improvisando nome para cada objeto ou seja, utilizou-se a comunicação visual para facilitar guardar ou estocar algum item. Desta forma, guardou-se os itens de acordo com a frequência de uso, conforme se observa no quadro 1.

Quadro 1: Frequência de uso e onde guardar

\begin{tabular}{|l|l|}
\hline Frequência de uso & Onde guardar \\
\hline Toda hora & No local de trabalho \\
\hline Todo dia & Próximo ao local de trabalho \\
\hline Toda semana & Almoxarifado \\
\hline Sem uso previsível & Em local fechado \\
\hline
\end{tabular}

Fonte: Rossato et al. (2016).

Para isso, analisou-se o layout das instalações (mesas, armários, área de estoque, ferramentas etc.) e dos equipamentos (máquinas, computadores, impressoras etc.). Além de verificar no ambiente de trabalho os arquivos e a comunicação visual (avisos, lembretes e comunicados). No terceiro passo, o senso de limpeza, foi feito o dia da limpeza e localizado quais as rotinas ou trabalhos que geram maior acúmulo de sujeira, modificando-as quando possível e exercendo a limpeza das mesmas. Este senso foi responsável pelo estado 
físico de tudo que se encontrava no ambiente de trabalho.

Para que se obtivesse êxito para colocar em prática o senso de limpeza e melhorar o ambiente de trabalho, tornando-o mais agradável e propício à saúde, foram listadas e executadas algumas atividades para o desenvolvimento do trabalho, como: estabelecimento de horários para que todos façam suas limpezas diárias; promoção da conscientização dos envolvidos para colaborarem com a limpeza do ambiente de trabalho e elaboração de listas para verificação de todos os pontos do trabalho que mereçam atenção especial durante a limpeza.

No quarto senso, o senso de padronização e saúde, procurou-se padronizar e manter os três primeiros sensos diariamente, além de cuidar do corpo e da mente de todos os colaboradores, assim, tentouse tornar saudável o ambiente de trabalho. Neste senso, também, avaliou-se os resultados anteriores já alcançados e verificou-se o que ainda poderia ser melhorado. Na figura 2, explica-se como foi feita a aplicação do quarto senso de maneira mais didática.

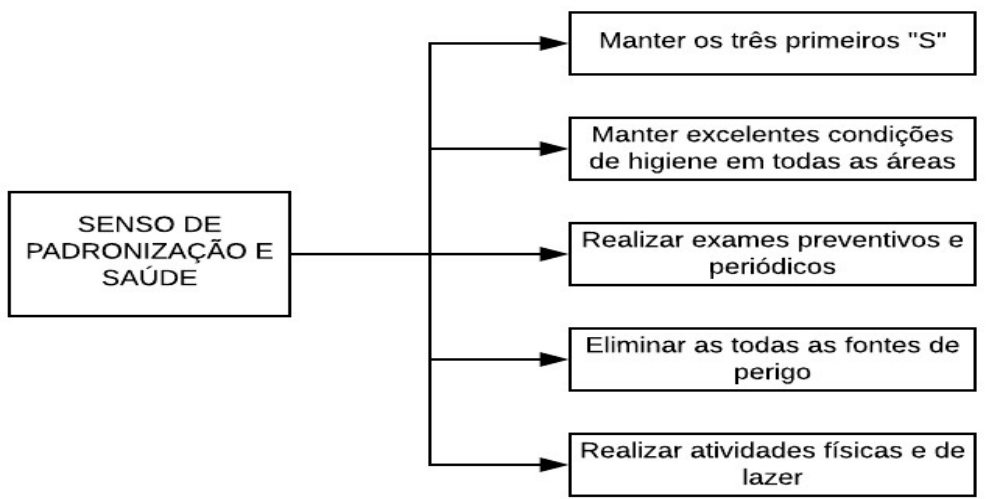

Figura 2: Ações elaboradas para a prática do senso de padronização e saúde. Fonte: Rossato et al. (2016).

No último senso, o senso de autodisciplina, criou-se uma rotina para constantemente buscar a melhoria alcançada. Nesse senso, realizaram-se auditorias periódicas dos $5 \mathrm{~S}$, por meio de práticas para verificar e manter os benefícios do programa. $\mathrm{O}$ acompanhamento da implantação do programa $5 \mathrm{~S}$ deve ser feita por meio de uma planilha de avaliação (quadro 3).

Quadro 3: Planilha de avaliação.

Existem materiais e equipamentos utilizados em situações de rotina espalhadas pelo chão, mesas ou pela área? Objetos de usos pessoal são guardados em local especifico?

Para todos os materiais e equipamentos existe local apropriado e definido para armazenagem?

Existe identificação de áreas, salas, equipamentos, armários ou gavetas, equipamentos de emergência etc.?

Mesas e armários estão em ordem durante e após a realização das atividades?

A quantidade de armários, prateleiras, cadeiras, coletores de lixo está adequada à necessidade?

Existem tubulações não protegidas, fios exposto ou material fora do local dificultando a passagem e possibilitando acidentes?

Fonte: Rossato et al. (2016).

Essa planilha de avaliação observada no quadro 3 tem como finalidade verificar e avaliar o senso de utilização e organização, pois se procura um alinhamento em todos os processos dentro da empresa, mantendo sempre em ordem os cinco sensos. Portanto, deve-se ter responsáveis para verificar o desempenho dos sensos na organização para manter as mudanças citadas acima em longo prazo. 


\section{RESULTADOS E DISCUSSÃO}

Esta pesquisa foi aplicada em um supermercado, localizado na cidade de Entre Rios do Oeste, com um quadro de funcionários de 14 pessoas. O estabelecimento foi fundado em julho de 1995, contando com 24 anos de atuação. Inicialmente, foi inaugurado em um local e, logo após, fez-se as devidas mudanças e ampliações necessárias. Para o decorrer do estudo, seguiu-se algumas etapas que estão descritas na metodologia do artigo. Após a realização da reunião com o gerente e com os colaboradosres do estabelecimento, para conscientização da importância da ferramenta 5S, iniciou-se a aplicação dos sensos.

\section{Senso de utilização}

Identificaram-se os itens necessários e desnecessários, mantendo apenas o que realmente tinha necessidade. Na figura 3, mostra-se o que foi eliminado.

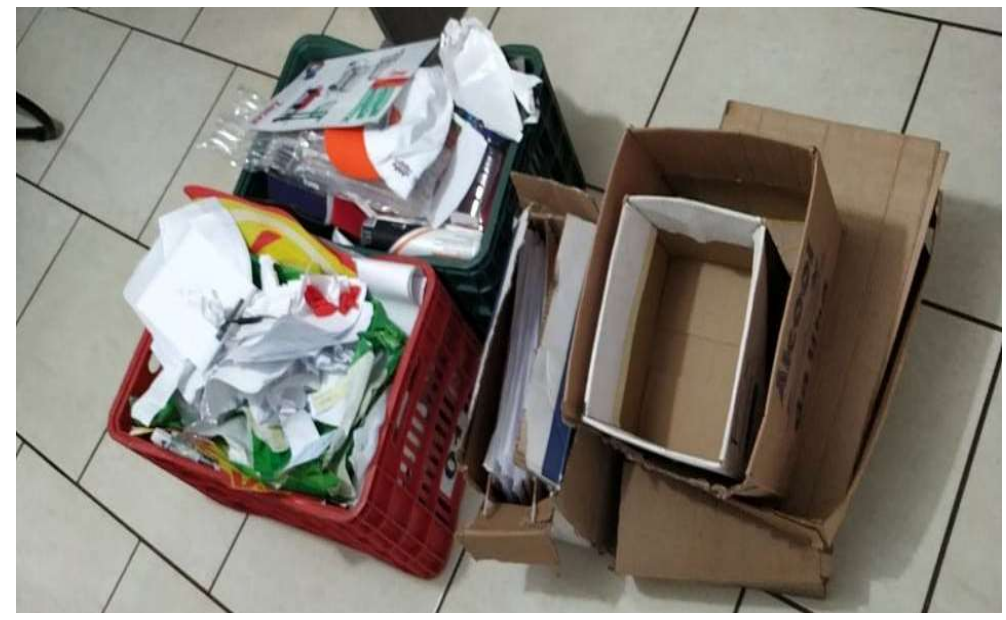

Figura 3: Itens eliminados.

\section{Senso de arrumação}

No segundo senso, organizou-se o ambiente de trabalho. Desta forma, guardaram-se os itens de acordo com a frequência de uso, conforme se observa nas figuras 4, 5 e 6 .

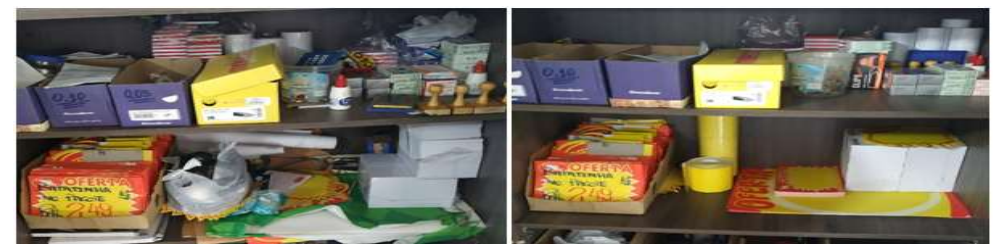

Figura 4: Aplicação do senso de arrumação.

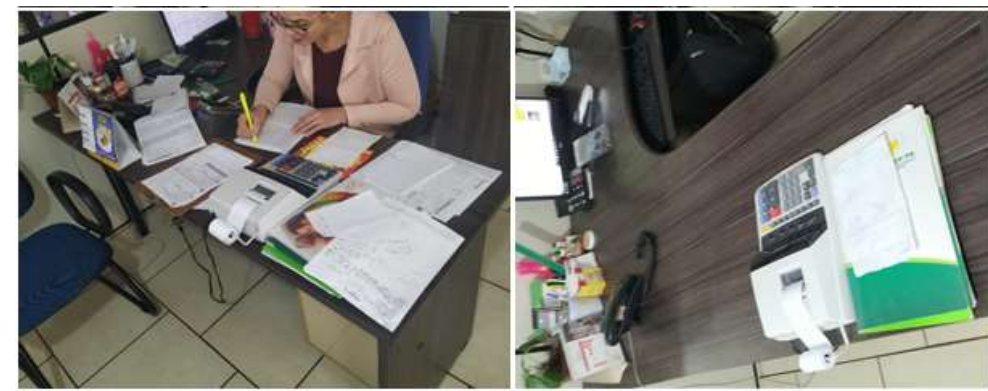

Figura 5: Aplicação do senso de arrumação. 

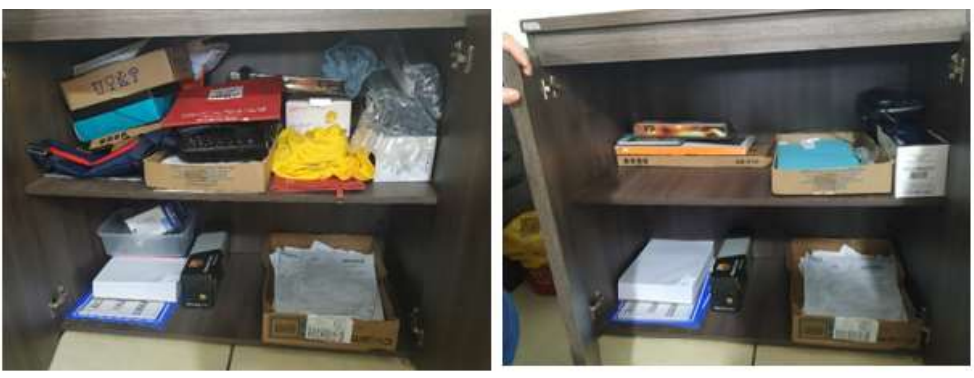

Figura 6: Aplicação do senso de arrumação.

Este senso teve extrema importância para o supermercado, pois os itens, antes da aplicação do programa, não eram muito organizadas, o que acabava dificultando o trabalho diário da equipe de funcionários. Antes, os estoques eram todos bagunçados, sem um padrão de organização, então, tentou-se organizar de acordo com a disposição das gôndolas dentro do supermercado. Por exemplo, todo o estoque ficou ordenado de acordo com as seções: limpeza, higiene pessoal, descartáveis, macarrão, chinelos e toalhas, artigos para casa (panelas, bacias, talheres, copos, pratos, etc.), enlatados, molhos e conservas, "pesados" (mantimentos básicos, como, farinha, açúcar, arroz, etc.), guloseimas, entre outras.

Além da parte física, foi feita, também, a organização do estoque, em que se realizou a contagem dos itens (balanço) e alinhou-os com o sistema, atividade que não havia sido feita desde 2012. Além disso, aproveitou-se para atualizar a validade dos itens. A partir da data da realização do estudo, o gestor começou a receber notificações do vencimento de todos os produtos um mês antes da data de validade expirar. Dessa forma, ele pode julgar por fazer uma oferta do produto ou, se ele acredita que vá vender, apenas ignorar o alerta, o que facilitou muito o controle sobre as trocas.

\section{Senso de limpeza}

No terceiro passo foi feito o dia da limpeza e localizado quais rotinas ou trabalhos que geram maior acúmulo de sujeira, modificando-as quando possível e exercendo a limpeza das mesmas. De segundas-feiras a sábados, no período da manhã, é realizada a limpeza do supermercado por uma zeladora contratada. 0 chão é limpo todos os dias e, com o restante do tempo que sobra, é feita a limpeza de outras áreas, como o estoque (segunda-feira, quando tem um nível menor de produtos e, consequentemente, mais espaço liberado), estacionamento (terça-feira), janelas e vitrine (quarta-feira), açougue (quinta-feira). De sexta-feira em diante, dá-se uma atenção especial para a área de atendimento, pois nesse período o nível de clientes e de vendas aumentam, o que possibilita, no tempo restante à limpeza do chão, a zeladora ajudar o verdureiro.

Identificou-se que a maior fonte de sujeira é o açougue, onde deve-se cuidar muito para deixar o ambiente limpo, principalmente para manter a qualidade dos produtos oferecidos ao cliente. Por isso, ao final de cada corte de carne, deve-se efetuar a limpeza dos aparelhos que foram usados (faca, serra, gancho, bacia, balcão, moedor, entre outros) e, ao menos uma vez por semana, deve ser feita a limpeza geral do ambiente.

Percebeu-se, ainda, o acúmulo de sujeira e de pó nas seções/prateleiras. Então, em conversa com os gestores, sugeriu-se exigir de cada colaborador o cuidado de uma seção. Como cada um tem a sua seção para 
solicitação dos produtos e, consequentemente, reposição dos mesmos, o responsável por essa tarefa, fará a limpeza do ambiente uma vez por mês. Antes, era realizada quando surgisse necessidade, mas é indispensável ter um dia fixo para tal ação.

\section{Senso de padronização e saúde}

No quarto senso, cuidou-se do corpo e da mente de todos os colaboradores, assim, tentou-se tornar saudável o ambiente de trabalho. Primeiramente, olhou-se a validade de todos os extintores do supermercado, realizando-se a troca de duas unidades e acrescentando mais uma unidade próxima ao local com maior risco (estoque de papel higiênico).

O estabelecimento possui dois estoques, um no térreo e outro no segundo piso, devido à falta de espaço. Então, já que os funcionários sobem e descem escadas para repor os itens na área de venda, alocouse produtos com pouco peso para cima, ou seja, trocaram-se as bebidas que estavam em cima, com os papeis higiênicos que estavam no estoque debaixo, para que não necessite de tanto esforço físico dos funcionários no momento de reposição dos itens.

Para melhorar o ambiente e evitar futuros problemas, chamou-se um eletricista para fazer uma revisão na parte elétrica do local. Encontrou-se muitos fios desencapados que poderiam causar curtos, desencadeando um incêndio ou algo do parecido, ainda, realizou-se uma dedetização na parte interna, tomando cuidado com os produtos alimentares.

Além disso, para também melhorar a segurança de todos, foi realizada a instalação de câmeras de vigilância em todas as partes do supermercado e foi feito o conserto do alarme, que estava com alguns sensores estragados. Além do aumento da segurança, as câmeras ajudaram a resolver furos de caixa, advindos de situações inadequadas na rotina, como a devolução ou cobrança de algum valor a mais do cliente ou dos funcionários.

\section{Senso de autodisciplina}

No último senso, tentou-se criar uma rotina para manter as melhorias alcançadas. Utilizou-se de auditorias periódicas dos 5S, em que os representantes farão uma vez por mês uma vistoria (todo o dia 15 de cada mês), verificando e mantendo os benefícios do programa. Para isso, foram utilizadas os painéis apresentados no método, na etapa do senso de autodisciplina (quadro 3).

\section{Vantagens}

Os benefícios obtidos na aplicação do programa 5S estão citados na tabela 1, e inter-relacionados com os cinco sensos do programa.

Tabela 1: Benefícios atingidos com a aplicação do 5S.

\begin{tabular}{|l|l|l|l|l|l|}
\hline Benefícios & Seiri & Seiton & Seiso & Seiketsu & Shitisuke \\
\hline Eliminação do desperdício & & $\mathrm{X}$ & & & $\mathrm{X}$ \\
\hline Otimização do espaço & $\mathrm{X}$ & $\mathrm{X}$ & & & $\mathrm{X}$ \\
\hline Melhoria nas relações humanas & & & $\mathrm{X}$ & $\mathrm{X}$ & $\mathrm{X}$ \\
\hline
\end{tabular}




\begin{tabular}{|l|l|l|l|l|l|}
\hline Prevenção de quebras & & $\mathrm{X}$ & & $\mathrm{X}$ & $\mathrm{X}$ \\
\hline Autodisciplina & & & & $\mathrm{X}$ & $\mathrm{X}$ \\
\hline Incremento da eficiência & $\mathrm{X}$ & $\mathrm{X}$ & $\mathrm{X}$ & $\mathrm{X}$ & $\mathrm{X}$ \\
\hline Aumento da produtividade & $\mathrm{X}$ & $\mathrm{X}$ & $\mathrm{X}$ & $\mathrm{X}$ & $\mathrm{X}$ \\
\hline Maior facilidade na tomada de decisões & $\mathrm{X}$ & $\mathrm{X}$ & & & $\mathrm{X}$ \\
\hline Melhoria da qualidade & $\mathrm{X}$ & $\mathrm{X}$ & $\mathrm{X}$ & $\mathrm{X}$ & $\mathrm{X}$ \\
\hline Padronização & & $\mathrm{X}$ & $\mathrm{X}$ & $\mathrm{X}$ & $\mathrm{X}$ \\
\hline Aumento da segurança & & $\mathrm{X}$ & $\mathrm{X}$ & $\mathrm{X}$ & $\mathrm{X}$ \\
\hline Racionalização do tempo & $\mathrm{X}$ & $\mathrm{X}$ & $\mathrm{X}$ & $\mathrm{X}$ & $\mathrm{X}$ \\
\hline
\end{tabular}

\section{CONCLUSÕES}

Este estudo objetivou analisar os resultados obtidos na aplicação da ferramenta administrativa $5 \mathrm{~S}$ no Supermercado Beira Lago. Inicialmente os passos para a realização do estudo foram explicados e, consequentemente, colocados em prática, comparando o antes e o depois da aplicação e apresentando as vantagens obtidas em cada etapa.

No senso de utilização, separou-se o útil e o inútil e foi realizado o descarte de itens desnecessários, o que facilitou as atividades cotidianas da empresa. No senso de arrumação, organizou-se o estoque de acordo com as seções: de limpeza, higiene pessoal, descartáveis, macarrão, chinelos e toalhas, artigos para casa (panelas, bacias, talheres, copos, pratos, etc.), enlatados, molhos e conservas, 'pesados' (mantimentos básicos, como, farinha, açúcar, arroz, etc.), guloseimas, entre outras. Além da parte física, realizou-se a contagem dos itens (balanço) e se alinhou a mesma com o sistema. Também foi efetuado o lançamento da validade dos itens, o que facilitou muito o controle sobre as trocas.

No terceiro passo (senso de limpeza,) foi feito o dia da limpeza e localizado quais rotinas ou trabalhos que geram maior acúmulo de sujeira e quais rotinas apresentam algum risco a todos os membros e clientes da organização, modificando-as quando possível e exercendo a limpeza das mesmas. No quarto senso (padronização e saúde), cuidou-se do corpo e da mente de todos os colaboradores, assim, importou-se em tornar saudável o ambiente de trabalho, localizando quais rotinas apresentavam algum risco aos membros ou clientes da organização, alterando-as se possível.

Por último, no senso de autodisciplina, criou-se uma rotina para manter as melhorias alcançadas. Utilizou-se de auditorias periódicas dos $5 \mathrm{~S}$, em que os representantes farão uma vez por mês uma vistoria (todo o dia 15 de cada mês), verificando e mantendo os benefícios do programa. Dessa forma, neste trabalho foi possível identificar em que a organização necessitava melhorar. Assim, as vantagens obtidas por meio da aplicação do programa foram: a eliminação do desperdício, a otimização do espaço, a melhora nas relações humanas, a prevenção de quebras, a autodisciplina, o incremento da eficiência, o aumento da produtividade, a maior facilidade na tomada de decisões, a melhora da qualidade, a padronização, o aumento da segurança e a racionalização do tempo, conforme observado na tabela 1, que descreve o que foi atingido a partir dos sensos do programa $5 \mathrm{~S}$.

Como limitação, observa-se que os resultados de aplicação deste estudo não podem ser generalizados para outros supermercados, pois foi aplicado em uma única empresa, sendo necessária a reaplicação do programa para posteriores comparações. Entretanto, esta pesquisa está disponível para a utilização em posteriores estudos e para melhorar a qualidade do serviço oferecido pelas empresas, que 
buscam, continuamente, utilizar-se do programa.

\section{REFERÊNCIAS}

BALLESTERO-ALVAREZ, M. E.. Gestão de qualidade, produção e operações. São Paulo: Atlas, 2010.

CARVALHO, K. A.. Gestão por processos organizacionais na Universidade de Brasília: estudo de caso. Dissertação (Mestrado) - Universidade de Brasília, Brasília, 2015.

CARVALHO, O.; VIANA, O.. Ecodesenvolvimento e equilíbrio ecológico: algumas considerações sobre o Estado do Ceará. Revista Econômica do Nordeste, Fortaleza, v.29, n.2, 1998.

CORAL, E.. Modelo de planejamento estratégico para a sustentabilidade empresarial. Tese (Doutorado em Engenharia da Produção) - Universidade Federal de Santa Catarina, Florianópolis, 2002.

COSTA, B. W. C.; SOUZA, F. A.. Análise do programa 5S e das aplicações da ferramenta da qualidade por alunos de engenharia de produção. In: SIMPÓSIO DE ENGENHARIA DE PRODUÇÃO DE SERGIPE, 9. Anais. Sergipe, 2017.

DAVENPORT, T. H.. Reengenharia de processos: como inovar na empresa através da tecnologia da informação. Rio de Janeiro: Campus, 1994.

DOMINGUES, F. M. F. V.; XAVIER, W. G.; BIROCHI, R.. Gestão por processos: uma análise da ferramenta de gestão utilizada no poder judiciário de Santa Catarina. Revista Eletrônica de Estratégia \& Negócios, v.8, n.1, p.199-238, 2015.

DUARTE, F.; DUARTE, L. C. S.; ECKHARDT, M.. Métodos para qualificar os resultados auditorias do programa 5S. In: ENCONTRO NACIONAL DE ENGENHARIA DE PRODUÇÃO ENEGEP, 23. Anais. Salvador, 2013.

FALCÃO JÚNIOR, M. A. G.; SANTOS, R. N. M.. A gestão de processos na análise das atividades de seleções públicas simplificadas: estudo de caso em uma prefeitura. Revista de Gestão e Tecnologia, v.6, n.2, p.6-19, 2016.

FREITAS, A. S.; VIEIRA, A. C. P.; ZILLI, J. C.; SCHNEIDER, M. D.. Análise da Implantação do Programa $5 S$ em uma Empresa de Motores Ferroviários no Sul de Santa Catarina. In: MOSTRA DE INICIAÇÃO CIENTÍFICA, PÓS-GRADUAÇÃO, PESQUISA E EXTENSÃO, 15. Anais. Caxias do Sul, 2015.

JURAN, J. M.; GRYNA, F. M.. Controle da qualidade: conceitos, políticas e filosofia da qualidade. São Paulo: McGrow Hill, 1991.

KAPUR, D.; et al. Food Safety Practices and $5 S$ Implementation in Storage Area of Foods Industry: A Case Study. International Journal of Scientific Research in Science and Technology, v.4, n.2, p.1019-1039, 2018.

LANCASTER, J. M.. Lean and Six Sigma in Hospitality Organizations: Benefits, Challenges, and Implementation. 2011.

LAPA, R. P.; BARROS FILHO, A.; ALVES, J. F.. Praticando os cinco sensos. Rio de Janeiro: Qualitymark, 1998.
LEVIS, M.; BRADY, M.; HELFERT, M.. Total quality management underpins information quality management. Journal of American Academy of Business, Cambridge, v.14, n.1, p.172-178, 2008.

LIMA, M. L. M.. Aplicabilidade do programa 5 S nos serviços de alimentação. Monografia (Especialização em Administração em Serviços de Alimentação) - Universidade Federal do Ceará, Fortaleza, 1998.

LIVRAMENTO, T. F. S.; OLIVEIRA, E. A. A. Q.; MORAES, M. B.. Empresas resilientes: o desafio de estabelecer uma cultura inovativa como fator de proteção. Latin American Journal of Business Management, Taubaté, v.6, n.2, p.237-255, 2015.

MARSHALL JUNIOR, I.; CIERCO, A. A.; ROCHA, A. V.; MOTA, E. B.; AMORIM, S. R. L.. Gestão da qualidade. 10 ed. Rio de Janeiro: FGV, 2011.

MATSUO, M.; NAKAHARA, J.. The effects of the PDCA cycle and OJT on workplace learning. The International Journal of Human Resource Management, v.24, n.1, p.195207, 2013.

MILLER, W.. A working definition for total quality management (TQM) researchers. Journal of Quality Management, v.1, n.2, p.149-159, 1996.

MODELL, S.. Bundling management control innovations: A field study of organisational experimenting with total quality management and the balanced scorecard. Accounting, Auditing \& Accountability Journal, v.22, n.1, p.59-90, 2009.

MOHAMMAD, A. A.. Approaching the Adoption of Lean Thinking Principles in Food Operations in Hotels in Egypt. Tourism Review International, v.21, n.4, p.365-378, 2017.

OLIVEIRA, D. P. R.. Administração de processos: conceitos, metodologia, práticas. 5 ed. São Paulo: Atlas, 2013.

PANCHAL, R. K.. Improving the organization through 5S methodology, Proceedings of the National Conference on Trends and Advances in Mechanical Engineering. Faridabad: YMCA University of Science \& Technology, 2012.

PATEL, V. C.; THAKKAR, H.. A Case Study: 5 S Implementation in Ceramics Manufacturing Company. Bonfring International Journal of Industrial Engineering and Management Science, v.4, n.3, p.132, 2014.

RAUPP, F. M.; BEUREN, I. M.. Metodologia da Pesquisa Aplicável às Ciências Sociais. 2006.

RORIZ, C.; NUNES, E.; SOUSA, S.. Application of Lean Production Principles and Tools for Quality Improvement of Production Processes in a Carton Company. Procedia Manufacturing, 2017.

ROSSATO, F.; BOLIGON, J. A. R.; MEDEIROS, F. S. B. M.. Estratégias para a implantação do programa $5 \mathrm{~S}$ em uma cooperativa. Latin American Journal of Business Management, v.7, n.2, p.27-49, 2016. 
SENTANIN, O. F.; CÉSAR, F. A. S.; JABBOUR, C. J. C.. BusinesS process management in a Brazilian public research centre. Business Process Management Journal, v.14, n.4, p.483496, 2008.

SHAH, D. B.; DESAI, S.. Total productive maintenance (TPM) implementation in a machine shop: A case study. Procedia Engineering, n.51, p.592-599, 2013.

SILVA, J. M.. 5S: Um programa passageiro ou permanente?. In: ENEGEP, Anais. 2001.

SINGH, J.; RASTOGI, V.; SHARMA, R.. Implementation of $5 S$ practices: A review. Uncertain Supply Chain Management, v.2, n.3, p.155-162, 2014.
SOROOSHIAN, S.; SALIMI, M.; BAVANI, S.; AMINATTAHERI,

H.. Case report: experience of $5 S$ implementation, 2012.

SORTE, W. F.. Standardisation for incremental innovation: a case study in the Brazilian automobile industry.

International Journal of Lean Enterprise Research, v.1, n.1, p.81-93, 2014.

THIOLLENT, M. Pesquisa-ação nas organizações. São Paulo: Atlas, 1997.

URBAN, W.. The lean management maturity self-assessment tool based on organizational culture diagnosis. ProcediaSocial and Behavioral Sciences, v.213, p.728-733, 2015. 